\title{
Morphology and molecular phylogeny reveal three new records of wild Mushrooms from India in Lactarius subgenus Russularia
}

\author{
Ishika Bera ${ }^{1}$ and Kanad Das ${ }^{2 *}$ \\ ${ }^{1}$ Central National Herbarium, Botanical Survey of India, P.O. - Botanic Garden, Howrah -711103, India. \\ ${ }^{2 *}$ Acharya Jagadish Chandra Bose Indian Botanic Garden, Botanical Survey of India, P.O. - Botanic \\ Garden, Howrah - 711103, India. \\ *Corresponding author: kanaddasbsi@gmail.com

\section{आकृति विज्ञान एवं आण्विक जातिवृत्त के आधार पर भारत से लैक्टेरियस उपवंश रुसुलेरिया में वन्य मशरूम के तीन नए अभिलेखों की प्राप्ति ईशिका बेरा एवं कनद दास}

\section{सारांश}

यह शोध पत्र भारतीय कवकजात में एक योगदान है। अरुणाचल प्रदेश के वन क्षेत्रों के सामान्य वृहतकवकीय सर्वेक्षण के दौरान लैक्टेरियस उपवंश रुसुलेरिया से तीन सदस्यों अर्थात एल. अम्बिगुअस, एल. हिरटीपीज और एल. केसियाई का संग्रहण किया गया। इन जातियों का विस्तृत आकारिकीय वर्णन, चित्रण और एनआर आईटीएस-आधारित जातिवृत्तीय आंकलन प्रस्तुत किया गया है। सभी तीनों जातियों को भारत से प्रथम बार अभिलेखित किया गया है।

\section{Abstract}

This paper is a contribution to the Indian mycobiota. During a routine macrofungal survey in the forested areas of Arunachal Pradesh, three members from Lactarius subg. Russularia i.e. L. ambiguus, L. hirtipes and L. kesiyae were collected. Detailed morphological descriptions, illustrations and nrITS-based phylogenetic estimation of these species are presented. All three species are reported for the first time from India.

Keywords: Arunachal Pradesh, Morphology, nrITS, Phylogenetic inference, Russulaceae

\section{INTRODUCTION}

Lactarius Pers. being one of the cosmopolitan genera in the family Russulaceae has been found to be associated with both the broadleaved trees and conifers. It has been divided into the three subgenera: $L$. subg. Russularia (Fr.) Kauffman, L. subg. Plinthogali (Burl.) Hesler \& A. H. Smith and L. subg. Lactarius (Fr. ex J. Kickx f.) Kauffman. Species representing subg. Russularia are morphologically characterized by the orange to orange-brown, yellowish to reddish brown coloured and short to medium sized fruit bodies with typically dry and smooth cap surfaces (Basso 1999; Heilmann-Clausen \& al., 1998; Wisitrassameewong \& al., 2015; 2016). The colour of the latex is generally white and unchanging on exposure in this group with few exceptions such as white to pale yellow latex in $L$. quietus (Fr.: Fr.) Fr. and L. decipiens Quél., white latex turning into straw yellow and sulphur yellow in $L$. tabidus Fr. and L. duplicatus A.H. Sm. respectively 


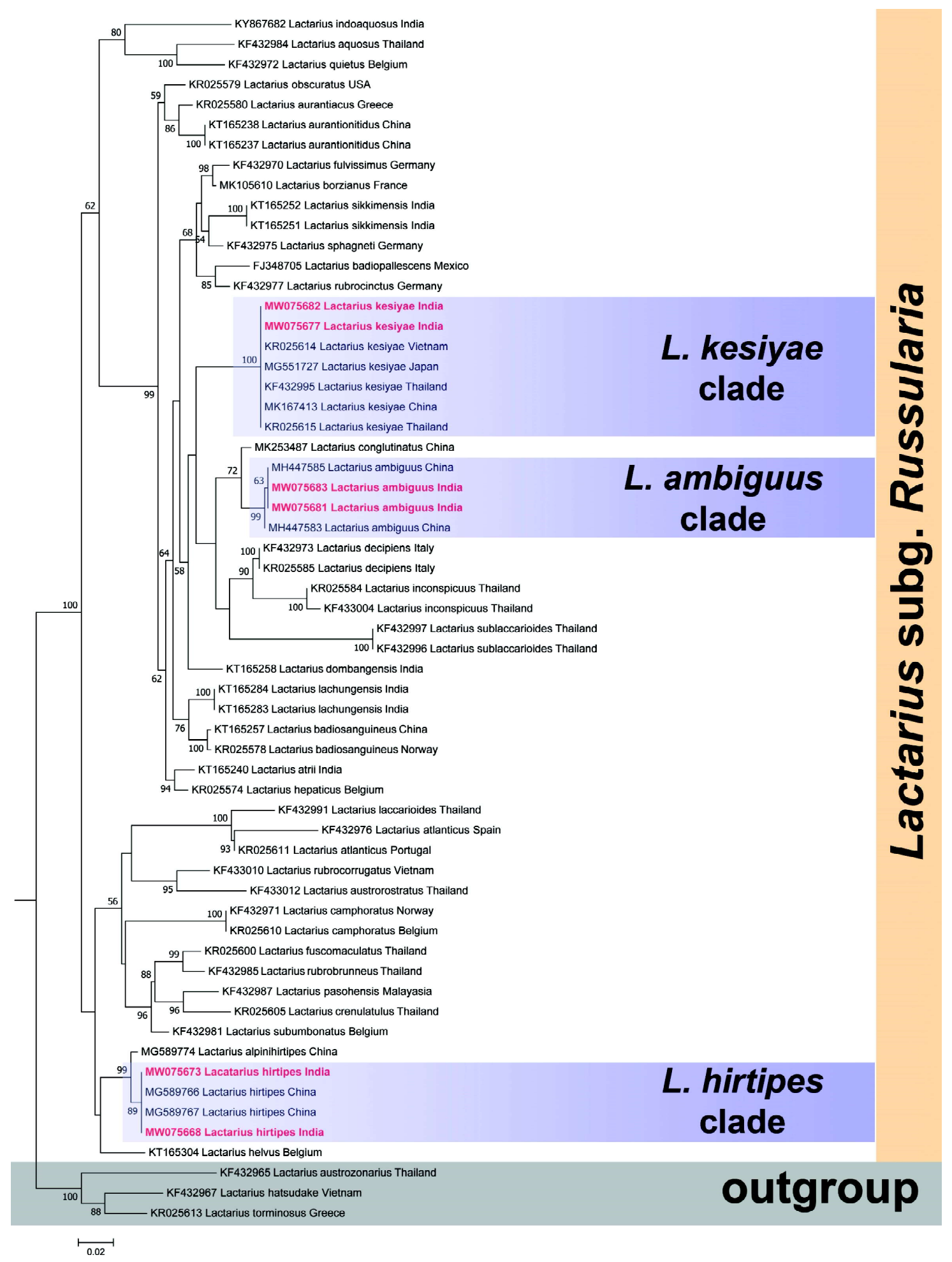

Fig. 1. Phylogram generated from ITS-rDNA sequences: The evolutionary history was inferred by using the Maximum Likelihood method in raxmlGUI 2.0 beta. Bootstrap support values ( $>50 \%$ ) obtained from the ML analysis are shown above or below the branches at nodes. 
(Heilmann-Clausen \& al., 1998; Wisitrassameewong \& al., 2019; Wisitrassameewong \& al., 2016). Hence, more comprehensive exploration is required to completely unravel its diversity in India. This present paper is contributing some addition to the diversity for the country. During the routine macrofungal surveys in the subtropical forests of Arunachal Pradesh, India which are dominated by Castanopsis and Pinus, some collections belonging to the subg. Russularia were made. A thorough morphological characterization (macro- and micromorphology) coupled with nrITSbased phylogenetic estimation revealed these taxa as $L$. ambiguus X.H. Wang, L. hirtipes J.Z. Ying and $L$. kesiyae Verbeken \& K.D. Hyde. All these three species are reported for the first time from India with a detailed morphological description and ITS-based phylogenetic inferences.

\section{MATERIAL AND METHODS}

\section{Morphological study}

Macromorphological features were recorded in the forest and in base-camp from the collected and dissected young to mature basidiomata. Images of the fresh basidiomata were captured with Nikon SLR D3400. Colour codes and terms used here are mostly after Methuen Handbook of Colour (Kornerup \& Wanscher, 1978). Micromorphological features were observed with a compound microscope (OLYMPUS CX-41). Free hand sections from dry specimens were mounted in a mixture of $5 \%$ potassium hydroxide $(\mathrm{KOH}), 1 \%$ Phloxine and $1 \%$ Congo red or in distilled water. Micromorphological drawings were made with a drawing tube (attached to the OLYMPUS CX-41) at $1000 \times$ magnification. All measurements were taken with the help of CellSens Standard software, dedicated to OLYMPUS BX-53. The basidium length excludes sterigmata. Basidiospore measurements were recorded in profile view from 40 basidiospores. Spore measurements and length/width ratios (Q) are recorded here as: minimum-mean-maximum. Herbarium codes follow Thiers (2021) (continuously updated). Microphotography is made with the help of a dedicated camera OLYMPUS DP-22 attached with compound microscope OLYMPUS BX-53.

\section{DNA extraction, PCR amplification and sequencing}

Genomic DNA was isolated from dry herbarium specimens (10-50 mg) using the Fungal gDNA Mini
Kit (RGCB, RFDF, Thiruvananthapuram). PCR protocol for the amplification of ITS1, 5.8S and ITS2 regions (nrITS) followed those in Das \& al., (2017). PCR products were duly purified using a QIAquick Gel Extraction Kit (QIAGEN, Germany) and subjected to automated DNA sequencing on an ABI3730xl DNA Analyzer (Applied Biosystems, USA) adding the same primers used earlier for amplification. The final consensus sequences were deposited at GenBank to procure the accession numbers: MW075681 and MW075683 for L. ambiguus, MW075668 and MW075673 for L. hirtipes, MW075677 and MW075682 for L. kesiyae.

\section{Phylogenetic analysis}

Phylogenetic analysis based on nrITS sequences data were carried out to establish the phylogenetic placement of our isolated taxa. The nrITS sequences of Indian Lactarius hirtipes, L. ambiguus and L. kesiyae plus similar ones from the subg. Russularia acquired from Blast search (Altschul \& al., 1997) against GenBank (Clark \& al., 2016) and relevant published phylogenies (Wisitrassameewong \& al., 2015; 2016) were aligned with the help of MAFFT v.7 (Katoh \& Standley, 2013). Aligned sequences were trimmed manually with MEGA7 (Kumar \& al., 2016). Final aligned sequences were edited manually with the help of BioEdit 7.2.5 (Hall 1999). Sequences of ITS were phylogenetically analyzed using Maximum Likelihood (ML). Maximum Likelihood (ML) was computed in raxmlGUI 2.0 (Edler \& al., 2019). One-thousand (1000) bootstrap replicates were analyzed to obtain nodal support values in case of ML analysis. We considered that clades with the bootstrap values exceeding $50 \%$ as well-supported.

\section{RESULTS}

\section{Phylogenetic inferences}

The final dataset consists of 60 nrITS sequences including our consensus sequences derived from Indian isolates. The phylogenetic tree (showing Indian collections in red and bold font) is presented in Fig 1. Sequences derived from Indian collections of $L$. hirtipes (MW075668 and MW075673) are nested within the L. hirtipes clade (indicated with a blue box) consisting of all the Chinese collections (representing MG589766 and MG589767 GenBank numbers) suggesting its strong similarity or conspecificity with the Indian species: L. hirtipes. Similarly, the sequences derived 


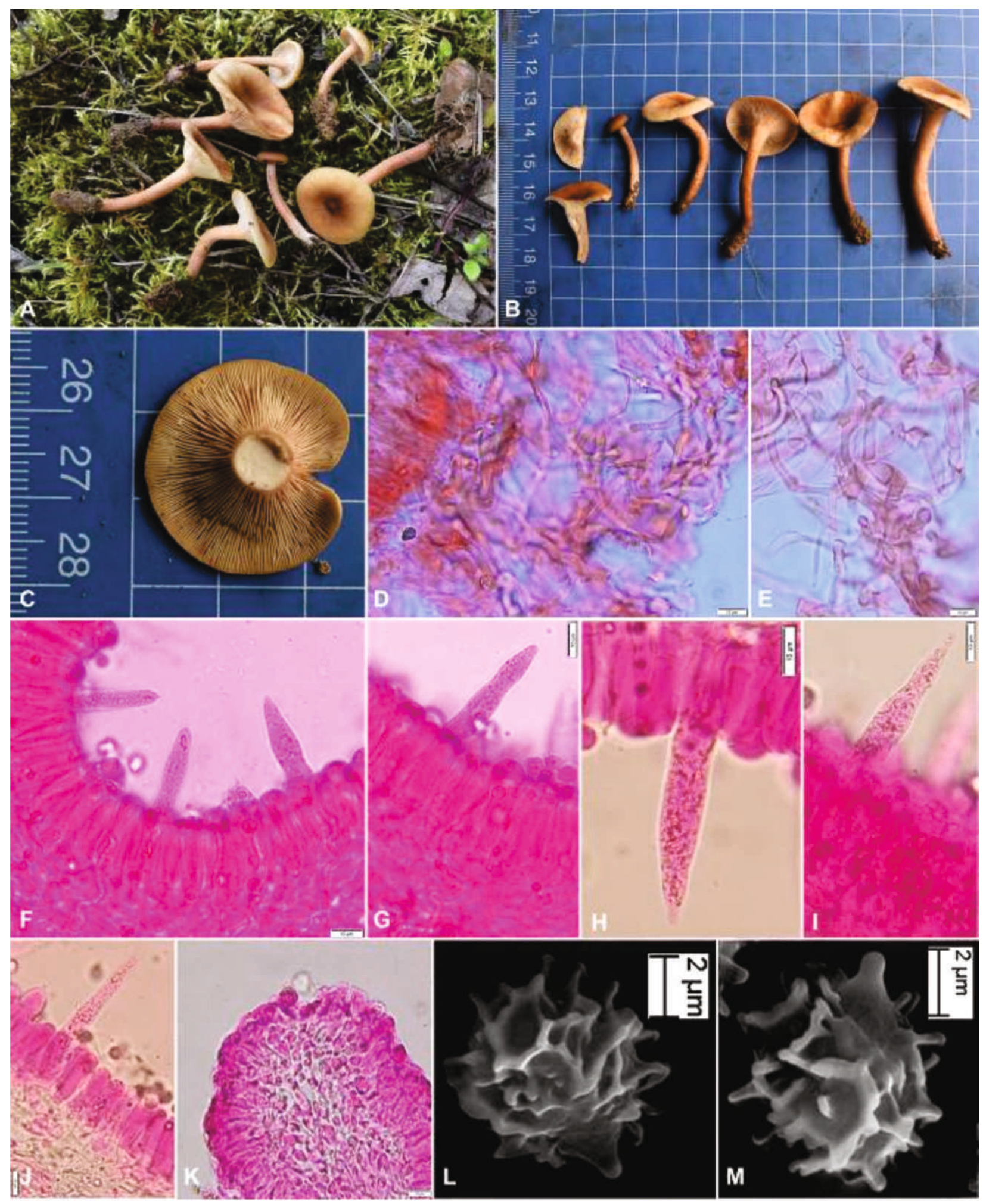

Fig. 2. Lactarius ambiguus (IB 19-023). A-C. Fresh basidiomata in the field and basecamp. D \& E. Transverse section through pileipellis. F-J. Pleuromacrocystidia. K. Transverse section through lamellae edge. L \& M. Basidiospore. Scale bars: $\mathbf{D}-\mathbf{K}=10 \mu \mathrm{m}, \mathbf{L} \& \mathbf{M}=2 \mu \mathrm{m}$. 
from the Indian collections of L. ambiguus (MW075681 and MW075683) are allied with its Chinese counterparts (MH447585 and MH447583) (indicated in a blue box). Likewise, the Indian collections of $L$. kesiyae (MW075677 and MW075682) are nested within the L. kesiyae clade consisting the other Asian collections (KR025614, MG551727, KF432995, MK167413 and KR025615) (indicated with a blue box).

\section{Taxonomy}

Lactarius ambiguus X.H. Wang, Cryptog. Mycol. 39 (2): 218 (2018)

(Fig. 2 \& 3)

Pileus 18-50 mm diam., convex with incurved margin with a central umbo when young, gradually becoming planoconvex to infundibuliform with broad central depression with much reduced umbo; surface dry, smooth; pilear surface light brown to yellowish brown (5D4-5) with light brown (5D5) and darker at the centre, gradually fading on maturity to brownish orange (5C5) and lighter, pale yellow to greyish yellow (4BA3) and paler at the margin; the cuticle not peeling easily; brittle in consistency; margin incurved when young, gradually becomes decurved, entire. Lamellae subdecurrent, rather crowded $(16 \mathrm{~L}+\mathrm{l} / \mathrm{cm}$ at pilear margin); rarely forked at the juncture of the stipe, lamellulae in 6 series, orange white (5A2) but turning brownish on bruising, edge entire. Stipe 50-85 × 6-10 $\mathrm{mm}$, central; cylindrical, surface dry, pruinose, greyish orange (5B3-4) gradually darker at base. Context moderately thin at pileus in comparison to the stipe, orange white (6A2), unchanged with $3 \% \mathrm{KOH}$, greenish with $\mathrm{FeSO}_{4}$, becoming brownish with guaiac. Latex scarce, slightly bitter, watery white, unchanging on exposure. Taste mild bitter. Odor fruity. Spore print not recorded.

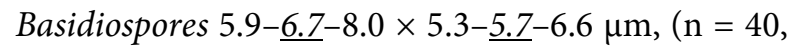
$\mathrm{Q}=1.05-1.16-1.24)$, usually globose to broadly ellipsoid; ornamentation amyloid, up to $0.7-1.2 \mu \mathrm{m}$ high, composed of ridges and medium elongate warts partly connected with connectors to form partially to almost complete reticulation, sometimes in a subzebroid pattern, isolated warts and free ridges present; suprahilar spot inamyloid. Basidia 45.0-52.2 $\times 9.5-11$ $\mu \mathrm{m}$, clavate, 4 -spored; sterigmata upto $2.5 \times 0.8 \mu \mathrm{m}$. Pleuromacrocystidia scarce to common, 58.0-87.8 $\times$ 7.1-9.7 $\mu \mathrm{m}$, emergent up to $44 \mu \mathrm{m}$, cylindric to subcylindric with fusoid, subfusoid to mucronate apices, thin-walled; content dense, granular to crystalline. Pleuropseudocystidia rare, up to $2.3 \mu \mathrm{m}$ wide, mostly non-emergent, cylindrical, sometimes tortuous at base.
Lamellae edge sterile. Cheilomacrocystidia not found. Subhymenium up to $22 \mu \mathrm{m}$ thick, cellular. Hymenophoral trama composed of lactifers and few nests of sphaerocytes connected with connecting hyphae. Pileipellis up to $81 \mu \mathrm{m}$ thick, an ixotrichoderm, suprapellis hairy, composed of interwoven, septate, mostly ascending hyphae, terminal cells of $20-88 \times$ 2.4-3.1 $\mu \mathrm{m}$, often intermixed with lactiferous hyphae. Stipitipellis up to $67 \mu \mathrm{m}$ thick, a cutis, composed of loose septate hyphae of 1.5-2 $\mu \mathrm{m}$ wide. Clamp connections absent in all tissues.

Habitat/distribution: Growing scattered on soil in association with a mixed forest of Castanopsis and Pinus sp. in subtropical Himalaya.

Specimens examined: INDIA, Arunachal Pradesh, West Kameng, Chug, $27^{\circ} 25.908^{\prime}$ N, $092^{\circ} 12.417^{\prime}$ E, 1761 $m$ a.s.l, $4^{\text {th }}$ August 2019, I. Bera, IB 19-023 (CAL 1828).

\section{DISCUSSION}

The combination of macro and micromorphological characters such as small to medium sized, dry basidiomata with a convex to planoconvex to infundibuliform, dry, smooth, light brown to yellowish brown coloured umbonate pileus with paler margin; greyish orange stipe; subdecurrent, rather crowded lamellae turning brownish on bruising; watery white unchanging latex, scarce pleuromacrocystidia mostly with mucronate apices and compactly arranged ixotrichoderm nature of pileipellis identify our Indian collections as L. ambiguuus. Morphology of the Indian materials are mostly in compliance with the holotype described from China (Wang \& al., 2018) which is furthermore strongly supported with our nrITS based phylogenetic estimation. Lactarius ambiguus from India are allied to the Chinese counterparts (represented by MH447585 and MH447583 in Fig. 1). But as mentioned in the description of the holotype by Wang \& al., (2018), a wide morphological variation was noticed within the specimens in L. ambiguus. Thus, identification becomes quite difficult based on only the morphological characterization.

An Asian species, L. tangerinus H.T. Le \& De Crop is quite similar to L. ambiguus due to its morphologically similar basidiomata, unchanging latex, subglobose to broadly ellipsoid basidiospores, pleuromacrocystidia with mucronate apices and trichoderm nature of the pileipellis (Wisitrassameewong \& al., 2015). But the presence of the umbonate pileus, longer pleuromacrocystida and the presence of the thin gluten 

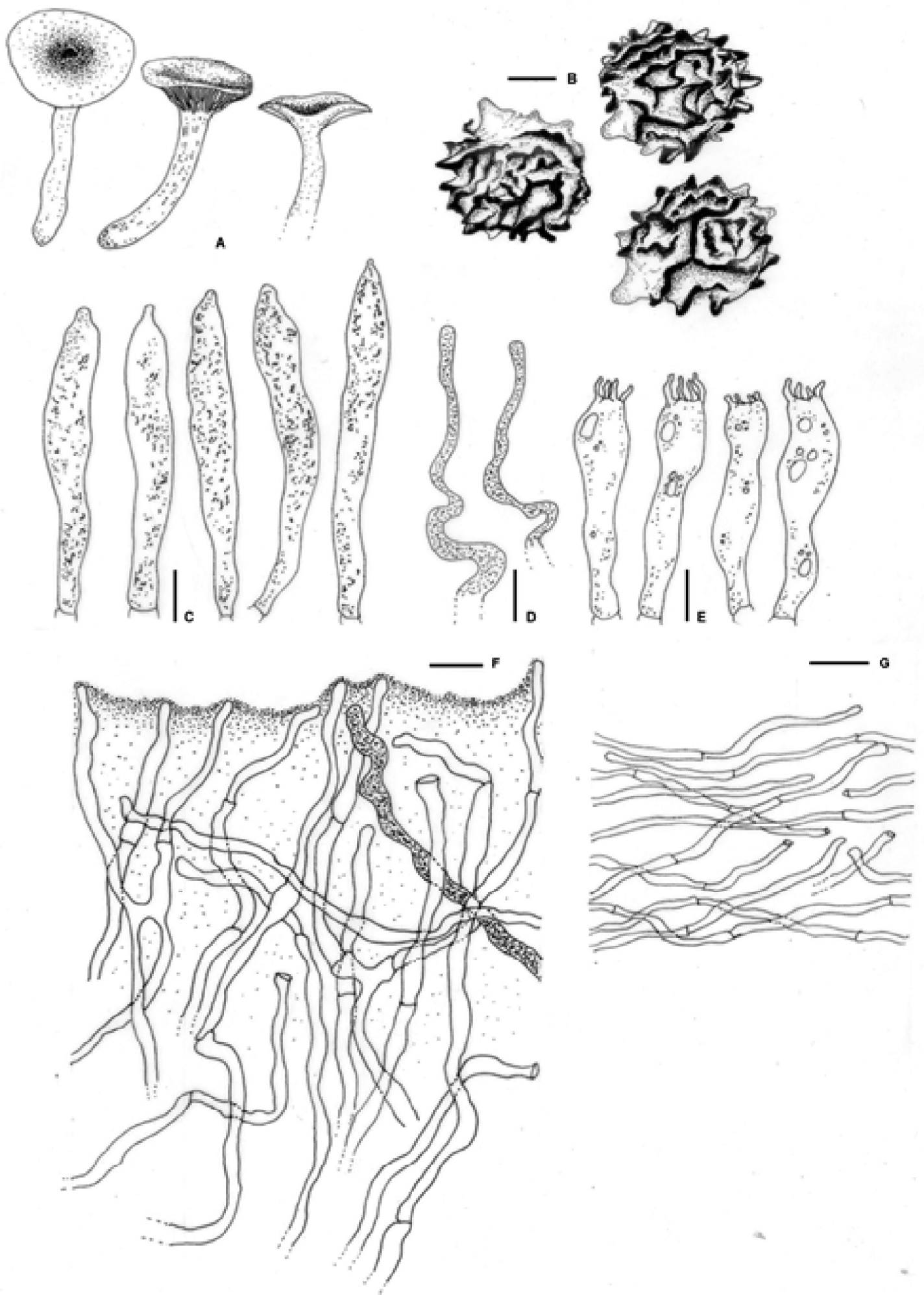

Fig. 3. Line drawings of Lactarius ambiguus (IB 19-023). A. Fresh basidiomata in the field and basecamp. B. Basidiospores. C. Pleuromacrocystidia. D. Pleuropseudocystidia. E. Basidia. F. Pileipellis. G. Stipitipellis. Scale bars: B $=2 \mu \mathrm{m} ; \mathbf{C}-\mathbf{G}=10 \mu \mathrm{m}$. 
layer certainly distinguish L. ambiguus from the former. Another Asian species, L. inconspicuus H.T. Le \& F. Hampe may get confused in terms of the similar looking cap surfaces with much darker centre and similar ixotrichoderm structure of the pileipellis, but the moist and viscid basidiomata, white latex turning pale yellow on exposure and a much thicker slime layer of the cutis make it quite distinct from L. ambiguus (Wisitrassameewong \& al., 2015).

Lactarius hirtipes J.Z. Ying, Acta Mycol. Sin. 10(3): 192 (1991)

(Fig. 4 \& 5)

Pileus 35-70 mm diam., convex with a central umbo when young, gradually becoming planoconvex at maturity, umbo may or may not persists; surface moist, viscid, mostly smooth to faintly rugulose graduating from centre, brownish orange (6C7) at centre with lighter towards margin; margin regular to wavy, sometimes cracked, decurved when young, incurved at maturity. Lamellae sub-decurrent, crowded (15 L+l / $\mathrm{cm}$ at pilear margin); lamellulae present in 5 series; edge entire; yellowish white (2A2). Stipe 35-100 × 6$7 \mathrm{~mm}$, central, cylindrical; surface viscid, smooth, concolorous to pileus, lighter near apex, white mycelium present at the base. Context in pileus thin, solid in stipe, orange white to pale orange (5A2-3), turning brownish after bruising, almost immediately turning bluish green in $\mathrm{FeSO}_{4}$ and unchanging in guaiac and $\mathrm{NH}_{4} \mathrm{OH}$. Latex scanty, watery white, unchanging on cut lamellae, taste mild acrid. Taste slightly acrid. Odor fruity. Spore print not found.

Basidiospores 5.7- $\underline{7.0}-7.9 \times 5.2-\underline{6.6}-7.3 \mu \mathrm{m},(\mathrm{n}=30$, $\mathrm{Q}=1.00-1.05-1.10$ ), usually globose to subglobose; ornamentation amyloid, up to $0.5 \mu \mathrm{m}$ high, composed of isolated warts and ridges that connected or aligned with connectors to form partially to almost complete reticulum; suprahilar spot inamyloid. Basidia 29.4-36.5 $\times 9.5-12 \mu \mathrm{m}$, subclavate, 4 -spored; sterigmata 1.5-6.7 $\times 1.1-1.7 \mu \mathrm{m}$. Pleuromacrocystidia common to abundant, $36.1-57.3 \times 3.1-6.3 \mu \mathrm{m}$, emergent up to 27.4 $\mu \mathrm{m}$, cylindric to subcylindric with rounded, acute, fusoid, subfusoid to mucronate apices, thin-walled; content dense, granular to fibrous. Pleuropseudocystidia scarce to moderate, up to $1.8 \mu \mathrm{m}$ wide, mostly non-emergent, cylindrical to slightly tortuous, with rounded apex. Lamellae edge fertile with basidia and basidioles. Cheilomacrocystidia not found. Subhymenium up to $21.5 \mu \mathrm{m}$ thick, cellular. Hymenophoral trama composed of lactifers and few nests of sphaerocytes connected with connecting hyphae. Pileipellis up to $68 \mu \mathrm{m}$ thick, an epithelium, composed of cellular to sub-cellular structure up to $28 \mu \mathrm{m}$ diam., terminal elements slightly elongated (3.5$12.5 \times 5.6-8 \mu \mathrm{m})$, no hyphal structure present. Stipitipellis composed of compactly and longitudinally arranged septate, sometimes inflated hyphae, rosettes of sphaerocytes not noticed. Clamp connections absent in all tissues.

Habitat/distribution: Growing scattered on soil in association with a mixed forest of Castanopsis and Pinus sp. in subtropical Himalaya.

Specimens examined: INDIA, Arunachal Pradesh, West Kameng, Sergaon, $27^{\circ} 07.623^{\prime} \mathrm{N}, 092^{\circ} 13.628^{\prime} \mathrm{E}, 2408 \mathrm{~m}$ a.s.l, $26^{\text {th }}$ July 2019, I. Bera, IB 19-008 (CAL 1829).

\section{DISCUSSION}

Lactarius hirtipes can easily be recognized in the field due to its bright brownish orange coloured slender smooth fruit bodies with watery white latex. Microscopically, globose to subglobose small basidiospores, absence of cheilomacrocystidia, pileipellis composed of cellular to non-cellular structures with no hyphal component and distinctively separated from the pilear trama and the longitudinally arranged hyphal structure of the stipitipellis make this taxon quite distinguished amongst others in subg. Russularia. Apart from the presence of a reduced umbo on the pileus (in some basidiomata), longer stipe and the unchanging latex, the Indian collections are in congruent with the Chinese counterparts (Wang \& Liu, 2002) which is also supported by our nrITS based phylogeney in Fig. 1. where L. hirtipes from India shows conspecifity with that of the Chinese collections (represented by MG589766 and MG589767).

Micromorphologically, L. hirtipes can be confused with the North American species, L. thiersii Hesler \& A.H. Sm., L. rufulus Peck and L. subserifluus Longyear due to the absence of any rosettes in the cortex of pileus and stipe. But the cinnamon coloured pileus in L. thiersii, larger basidiospores $(7-9.5 \times 7-9.5 \mu \mathrm{m})$ in $L$. rufulus and rusty orange coloured pileus in $L$. subserifluus separate these species from $L$. hirtipes (Wang \& Liu, 2002). Another species (originally described from China), L. chichuensis W.F. Chiu resembles $L$. hirtipes because of the similar coloured and smooth surfaced basidiomata, the association with the subtropical deciduous trees and the alike pattern of the pileipellis and stipitipellis. But it becomes distinguished due to the following characters: the shorter stipe $(30-55 \mu \mathrm{m})$, subglobose to broadly ellipsoid 


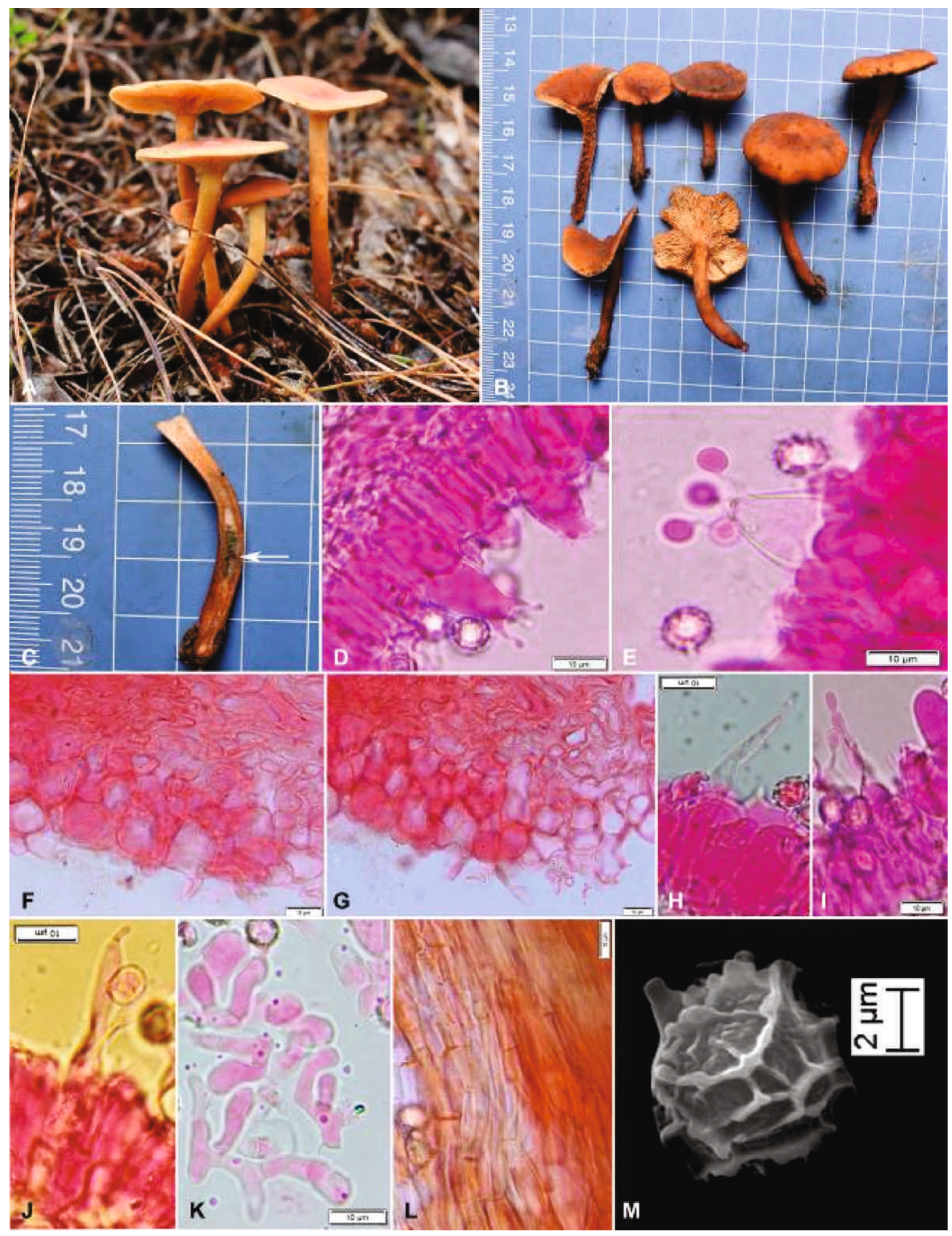

Fig. 4. Lactarius hirtipes (IB 19-008). A \& B. Fresh basidiomata in the field and basecamp. C. Macrochemical test with FeSO on context. D \& E. Hymenial layer showing basidia. F \& G. Transverse section through pileipellis. H-J. Pleuromacrocystidia. K. Marginal cells in the lamellar edge. L. Transverse section through stipitipellis. $\mathbf{M}$. Basidiospore. Scale bars: $\mathbf{D}-\mathbf{L}=10 \mu \mathrm{m}$, $\mathbf{M}=2 \mu \mathrm{m}$. 
basidiospores with zebroid ornamentation (partially to almost completely reticulate in $L$. hirtipes), larger pleuromacrocystidia $(47-90 \times 6-12 \mu \mathrm{m})$ and stipe cortex with rosettes of sphaerocytes (Wang \& Liu, 2002). Moreover, the cellular nature of the pileipellis is quite similar to that of an Indian species $L$. dombangensis Verbeken \& Van de Putte, but its much smaller pileus (2-5 $\mathrm{mm}$ diam.), crenulate margin and distant lamellae makes this species quite distinct in the field itself. L. flavigalactus Verbeken \& K. Das, another species from India may appear close to L. hirtipes in the field due to its reddish brown basidiomata with or without a reduced umbo but the yellowing latex and ixocutis pattern of the pileipellis certainly differentiate it from the latter (Wisitrassameewong \& al., 2016).

Lactarius kesiyae Verbeken \& K.D. Hyde, Phytotaxa 207(3): 229 (2015)

(Fig. 6 \& 7)

Pileus 42-105 mm diam., hemispheric to planoconvex with a central umbo when young, gradually becoming uplifting to infundibuliform with a wide central depression, sometimes umbo persists; surface moist, slightly viscid, smooth when young, heavy wrinkles along the margin on maturity, combination of yellowish grey and light blond (3B2 and 4C3) with light orange (5A4) at the centre, margin becoming yellowish grey (2B2) and lighter with a much darker centre on maturity, greyish orange (5B4) spots are seen in the matured basidiomata; margin entire to pectinate, incurved. Lamellae adnate to subdecurrent, close (12 $\mathrm{L}+\mathrm{l} / \mathrm{cm}$ at pilear margin); lamellulae present in 4-5 series; edge entire; yellowish grey (2B2) and lighter, gradually becoming darker with maturity. Stipe 55-85 $\times 10-25 \mathrm{~mm}$, central to eccentric, cylindrical; surface viscid or sticky, light orange to greyish orange (5AB5) with lighter at apex and gradually becoming darker towards base, surface pruinose. Context in pileus thin, hollow in stipe, yellowish white (1-2A2), almost immediately turning greenish in guaiac, brownish olive green in $\mathrm{FeSO}_{4}$ and unchanging in $\mathrm{NH}_{4} \mathrm{OH}$. Latex watery white, turning pale yellow to light yellow (2A34) on cut lamellae. Taste quite bitter. Odor fruity. Spore print not found.

Basidiospores 6.0- $\underline{7.5}-9.5 \times 5.0-\underline{6.3}-8.0 \mu \mathrm{m},(\mathrm{n}=30$, $\mathrm{Q}=1.05-1.18-1.35$ ), usually subglobose to ellipsoid; ornamentation amyloid, up to 1.1-1.7 $\mu \mathrm{m}$ high, composed of isolated warts and ridges that connected or aligned with connectors in a zebroid pattern to form partially to incomplete reticulum; suprahilar spot inamyloid. Basidia 35.4-41.8 × 8.8-9.8 $\mu \mathrm{m}$, subclavate, 4 -spored; sterigmata $1.8-2.0 \times 0.9-1.2 \mu \mathrm{m}$.
Pleuromacrocystidia abundant, 52.0-80.6 × 4.6-9.4 $\mu \mathrm{m}$, emergent up to $41.4 \mu \mathrm{m}$, subcylindric with fusoid, subfusoid, mucronate, subcapitate to appendiculated apices, thin-walled; content dense, granular to fibrous. Pleuropseudocystidia abundant, 1.7-2.2 $\mu \mathrm{m}$ wide, mostly non-emergent, cylindrical to slightly tortuous, with rounded apex. Lamellae edge fertile with basidia, basidioles and cystidia. Cheilomacrocystidia rare, 39.3$51.2 \times 4.6-5.8 \mu \mathrm{m}$, emergent up to $32 \mu \mathrm{m}$, subcylindric with subfusoid to appendiculated apices, thin-walled; content dense, granular to fibrous. Subhymenium up to $15 \mu \mathrm{m}$ thick, cellular. Hymenophoral trama composed of lactifers and few nests of sphaerocytes connected with connecting hyphae. Pileipellis up to $112.7 \mu \mathrm{m}$ thick, an ixotrichoderm, suprapellis hairy, composed of interwoven, septate, mostly ascending hyphae intermixed with lactiferous hyphae (10.6-25.2 $\times 1.7-2.9 \mu \mathrm{m})$. Stipitipellis up to $38.8 \mu \mathrm{m}$ thick, ixocutis; composed of interwoven, septate hyphae. Clamp connections absent in all tissues.

Habitat/distribution: Growing scattered on soil in association with Pinus sp. in a mixed deciduous forest in subtropical Himalaya.

Specimens examined: INDIA, Arunachal Pradesh, West Kameng, Dirang, Namchu, 27 $21.155^{\prime} \mathrm{N}$, $092^{\circ} 18.942^{\prime} \mathrm{E}, 1968 \mathrm{~m}$ a.s.l, $2^{\text {nd }}$ August 2019, I. Bera, IB 19-019 (CAL 1830).

\section{DISCUSSION}

Lactarius kesiyae Verbeken \& K.D. Hyde can be recognised in the field by its medium sized fruit bodies (pileus 42-105 mm diam., stipe 55-85 × 10-25 mm), smooth, viscid, moist, yellowish gray and light blond coloured, sometimes umbonate cap surfaces with light orange at the centre, entire to pectinate margin, light orange to greyish orange stipe, watery white latex changing to pale yellow on exposure, adnate to subdecurrent lamellae and its occurrence under Pinus sp. Microscopically, a much emergent and long pleuromacrocystidia $(52.0-80.6 \times 4.6-9.4 \mu \mathrm{m})$ and cheilomacrocystidia (39.3-51.2 $\times 4.6-5.8 \mu \mathrm{m})$ and an ixotrichoderm nature of pileipellis make this species more identifiable. Morphologically, the Indian collection is mostly in conformity with the holotype described from Vietnam (Wisitrassameewong \& al., 2015). Moreover, our nrITS-based phylogeny strongly shows the conspecificity of our collections to the Vietnamese counterpart of L. kesiyae (represented by KR025614 in Fig. 1), and other Asian collections from Japan, Thailand and China (MG551727, KF432995, 

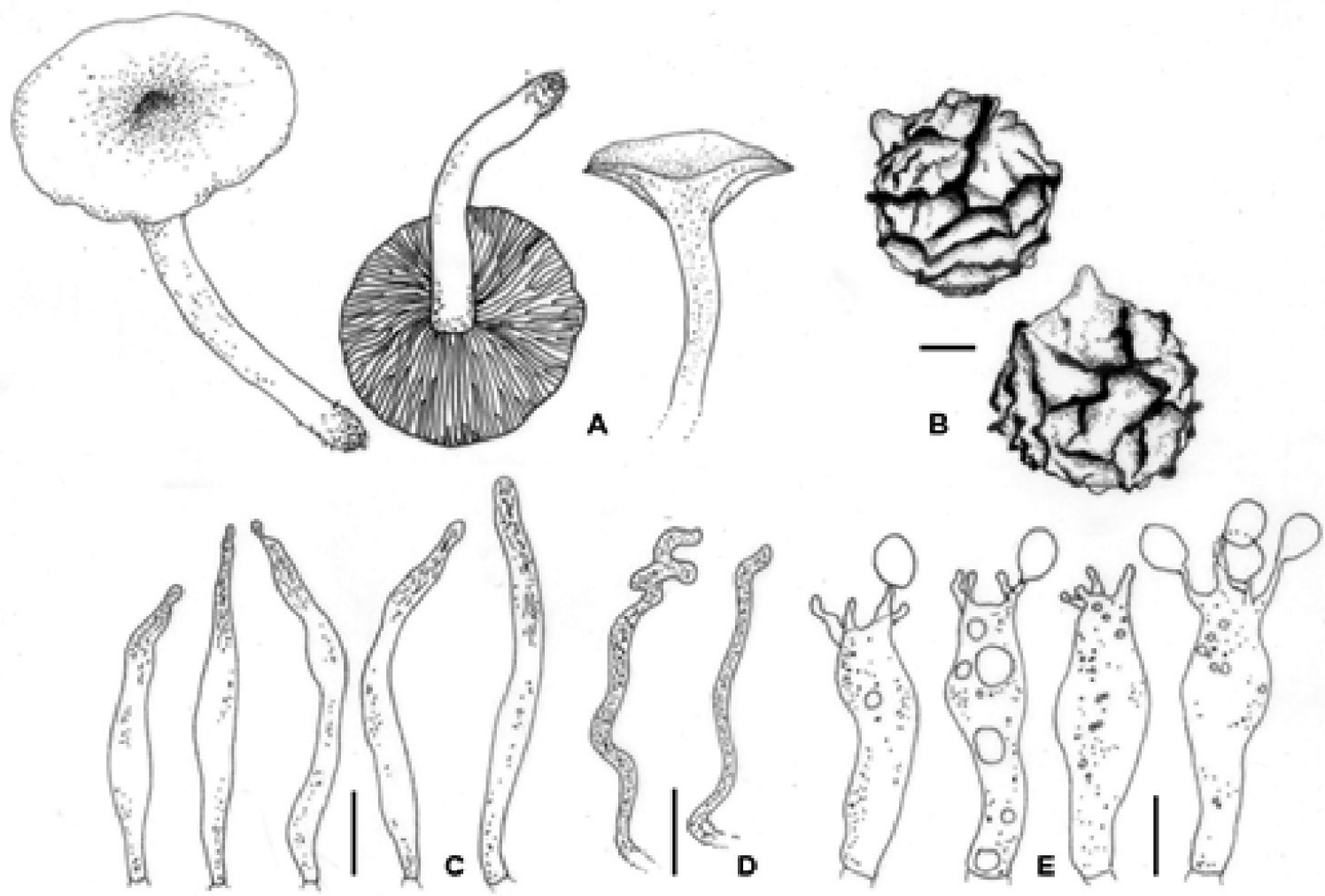

$\mathbf{F}$
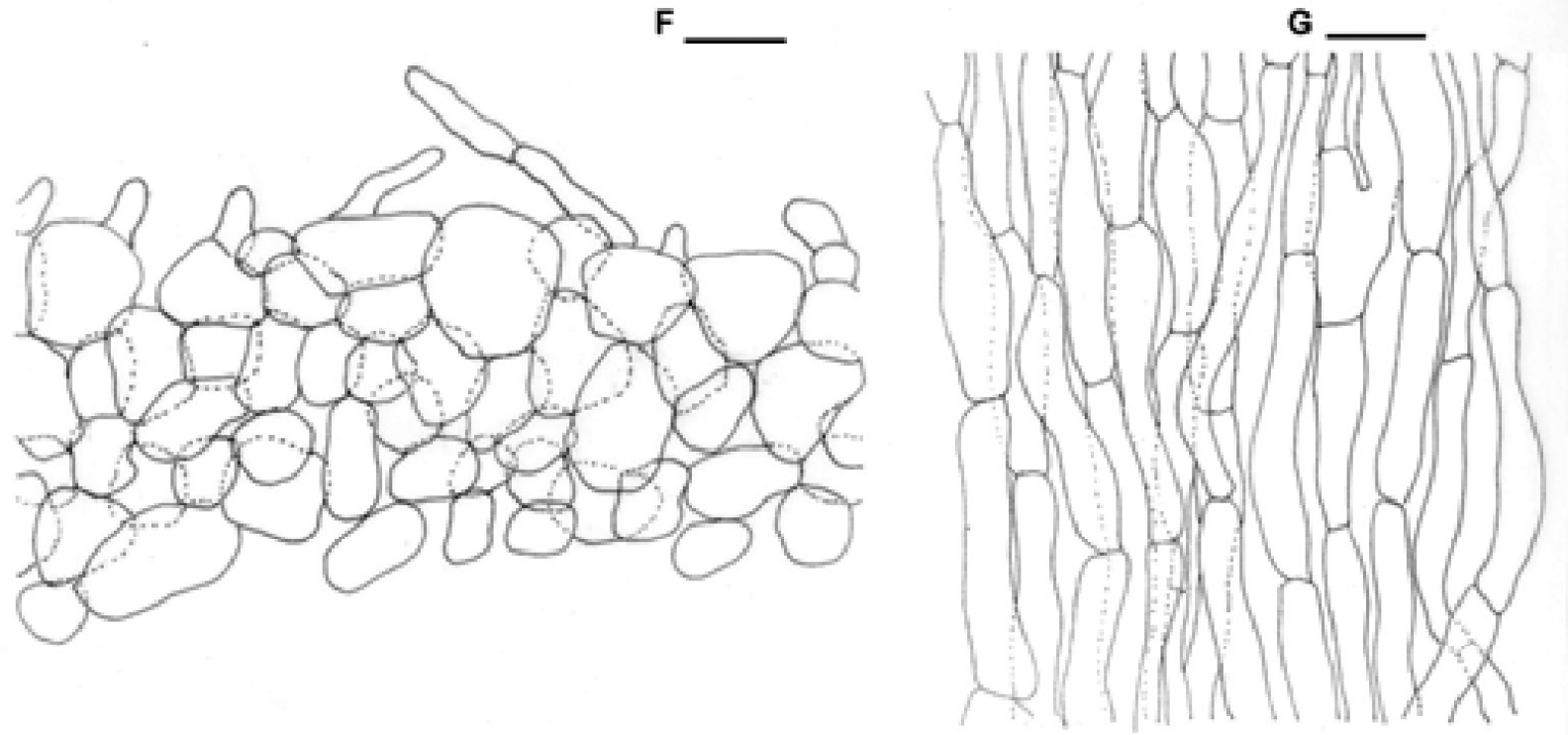

Fig. 5. Lactarius hirtipes (IB 19-008). A. Fresh basidiomata in the field and basecamp. B. Basidiospores. C. Pleuromacrocystidia. D. Pleuropseudocystidia. E. Basidia. F. Pileipellis. G. Stipitipellis. Scale bars: $\mathbf{B}=2 \mu \mathrm{m} ; \mathbf{C}-\mathbf{G}=10 \mu \mathrm{m}$. 


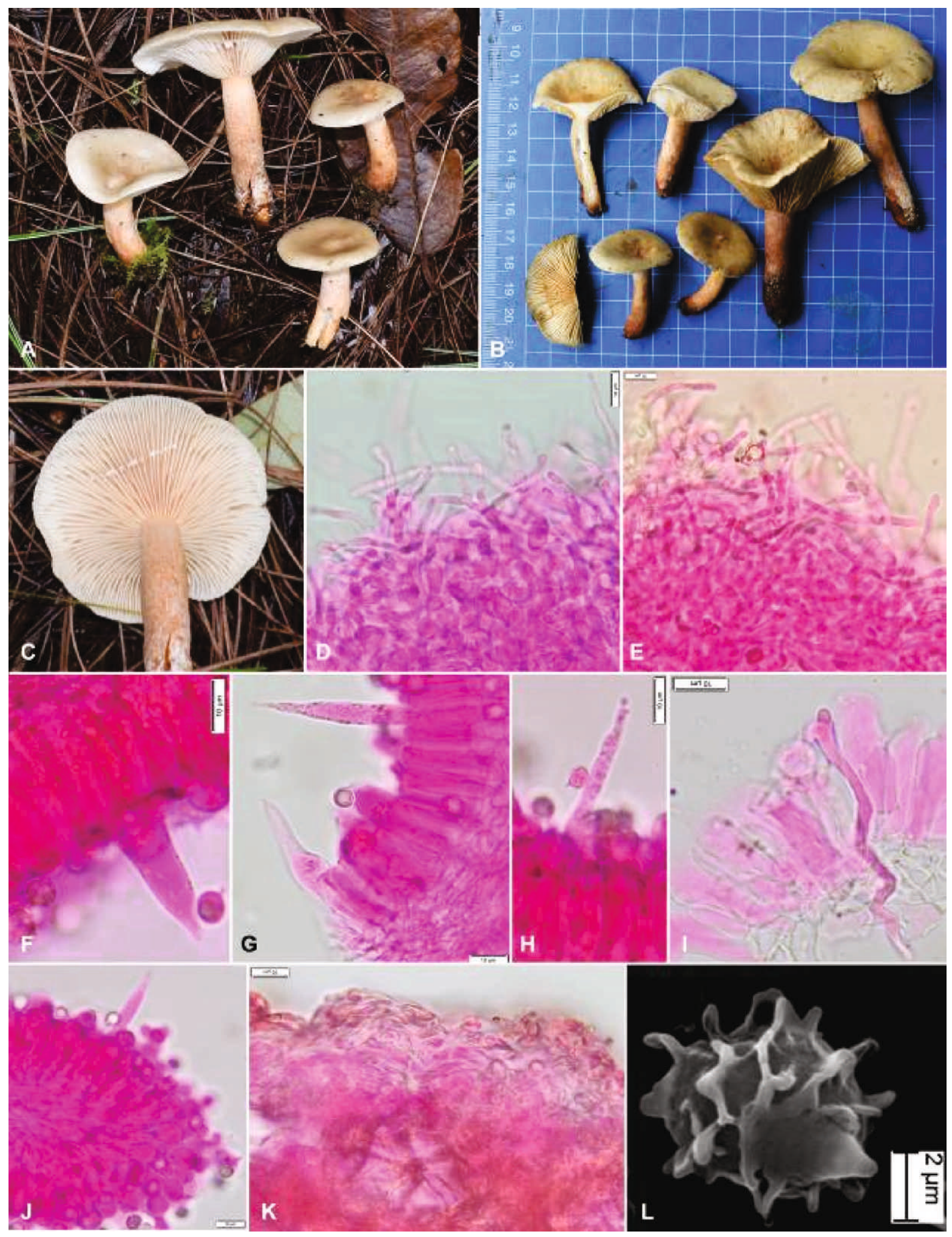

Fig. 6. Lactarius kesiyae (IB 19-019). A-C. Fresh basidiomata in the field and basecamp. D \& E. Transverse section through pileipellis. F-H. Pleuromacrocystidia. I. Pleuropseudocystidia. J. Cheilomacrocystidia. K. Transverse section through stipitipellis. L. Basidiospore. Scale bars: $\mathbf{D}-\mathbf{K}=10 \mu \mathrm{m}, \mathbf{L}=2 \mu \mathrm{m}$. 


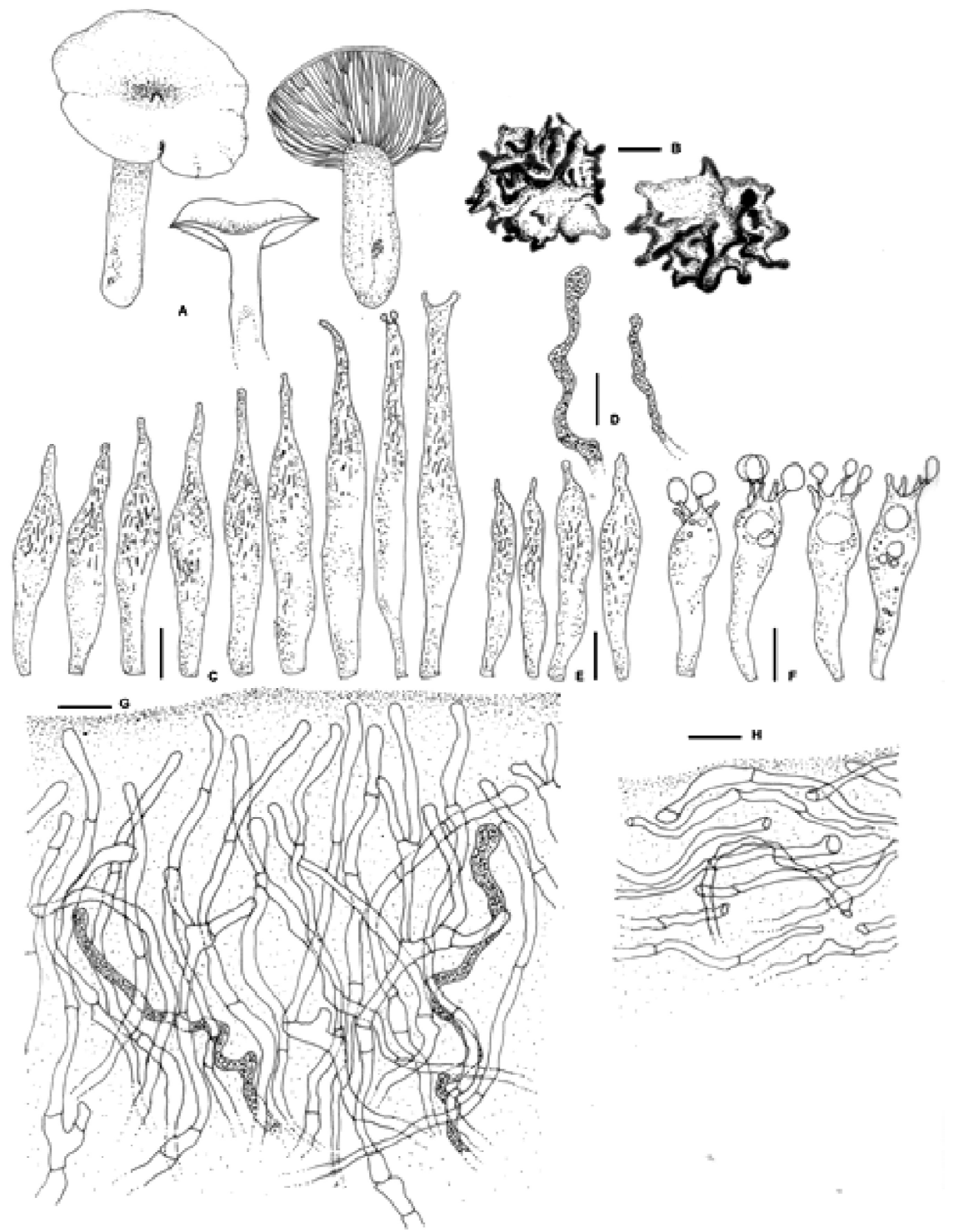

Fig. 7. Lactarius kesiyae (IB 19-019). A. Fresh basidiomata in the field and basecamp. B. Basidiospores. C. Pleuromacrocystidia. D. Pleuropseudocystidia. E. Cheilomacrocystidia. F. Basidia. G. Pileipellis. H. Stipitipellis. Scale bars: $\mathbf{B}=2 \mu \mathrm{m} ; \mathbf{C}-\mathbf{H}=10 \mu \mathrm{m}$.

KR025615 and MK167413 respectively in Fig. 1). However, the Indian specimens show comparatively larger basidiomata, close lamellae $(12 \mathrm{~L}+1 / \mathrm{cm}$ at pilear margin) with lamellulae in $4-5$ series.

Though the ixotrichoderm pattern of the pileipellis is similar to that of the members of $L$. subg. Lactarius, but in few temperate species from Europe and North America like L. decipiens Quel., L. badiosanguineus Kühner \& Romagn. and L. duplicatus A.H. Sm. such viscid pileus surfaces have been found. However, morphologically, these species are quite distinct from
L. kesiyae. Similar characters of L. inconspicuus H.T. Le \& F. Hampe like medium sized basidiomata with sticky moist umbonate pileus, white latex changing to pale yellow, long protruding pleuromacrocystidia and ixotrichoderm nature of pileipellis make it confused with L. kesiyae (Wisitrassameewong \& al., 2015). But darker coloured cap surface, dissimilar macrochemical colour reactions on context (light brown with $\mathrm{KOH}$ and greyish yellow with $\mathrm{FeSO}_{4}$ ) and its association with Castanopsis make L. inconspicuus completely distinct from L. kesiyae (Wisitrassameewong \& al., 2015). 


\section{ACKNOWLEGDEMENTS}

The authors are grateful to the Director, Botanical Survey of India (Kolkata) for providing facilities. IB \& $\mathrm{KD}$ are thankful to the entire forest department of Arunachal Pradesh for allowing them to undertake the macrofungal surveys to the restricted areas.

\section{REFERENCES}

ALTSCHUL, S.F., T.L. MADDEN, A.A. SCHAFFER, J. ZHANG, Z. ZHANG, W. MILLER AND D.J. LIPMAN 1997. Gapped BLAST and PSI-BLAST: a new generation of protein database search programs. Nucleic acids research 25(17): 3389-3402.

BASSO, M.T. 1999. Lactarius Pers. Fungi Europaei. Vol. 7. Ed. Libreria Mykoflora. Alassio.

CHIU, W.F. 1945. The Russulaceae of Yunnan. Lloydia 8(3).

CLARK, K., I. KARSCH-MIZRACHI, D.J. LIPMAN, J. OSTELL AND E. W. SAYERS 2016. GenBank. Nucleic acids research 44(D1): D67-D72. https://doi.org/ 10.1093/nar/gkv1276

DAS, K., J.R. SHARMA AND L. MONTOYA 2004. Lactarius (Russulaceae) in Kumaon Himalaya. 1. New species of subgenus Russularia. Fungal Diversity 16(2).

DAS, K. AND J.R. SHARMA 2005. Russulaceae of Kumaon Himalaya. Botanical Survey of India, Ministry of Environment \& Forests, Kolkata - 700 064, India, $255 \mathrm{pp}$.

DAS, K., A. VERBEKEN AND J. NUYTINCK 2015. Morphology and phylogeny of four new Lactarius species from Himalayan India. Mycotaxon 130 (1): 105130.

DAS, K., A. VERBEKEN, D. CHAKRABORTY, R. AVCHAR AND A. BAGHELA 2017. Morphological and phylogenetic evidence for two new Lactarius species (Russulales, Basidiomycota) from India. Cryptogamie, Mycologie 38(4): 453-467. https://doi: $10.1101 / 800912$

EDLER, D., J. KLEIN, A. ANTONELLI AND D. SILVESTRO 2019. raxmlGUI 2.0 : a graphical interface and toolkit for phylogenetic analyses using RAxML. bioRxiv. https://doi. org/10.1101/800912.
HALL, T.A. 1999. BioEdit: a user-friendly biological sequence alignment editor and analysis program for Windows 95/98/NT. In Nucleic acids symposium series (Vol. 41, No. 41, pp. 95-98). [London]: Information Retrieval Ltd., c1979-c2000.

HEILMANN-CLAUSEN, J., A. VERBEKEN AND J. VESTERHOLT 1998. The Genus Lactarius (Fungi of Northern Europe, Vol. 2). Danish Mycological Society, Copenhagen.

HESLER, L. R. AND A.H. SMITH 1979. North American species of Lactarius. University of Michigan Press.

HONGO, T. 1957a. Notes on Japanese larger fungi 10. Journal of Japanese Botany 32: 144.

HONGO, T. 1957b. Notes on Japanese larger fungi 11. Journal of Japanese Botany 32 (7): 213.

HONGO, T. 1971. Notulae mycologicae 10. Memoirs of Shiga University 21: 62-68.

KATOH, K. AND D.M. STANDLEY 2013. MAFFT multiple sequence alignment software ver. 7 : improvements in performance and usability. Mol. Biol. Evol.30: 772-780.

KORNERUP, A. AND J.H. WANSCHER 1978. Methuen handbook of color. Eyre Methuen, London, 252 pp.

KUMAR, S., G. STECHER AND K. TAMURA 2016. MEGA7: molecular evolutionary genetics analysis ver. 7.0 for bigger datasets. - Mol. Biol. Evol. 33: 18701874.

MONTOYA, L., V.M. BANDALA AND E. GARAY 2014. Two new species of Lactarius associated with Alnus acuminata subsp. arguta in Mexico. Mycologia 106(5): 949-962.

PALOI, S., A. VERBEKEN AND K. ACHARYA 2019. Lactarius brunneocinnamomeus, a new species of Lactarius subgenus Russularia from West Bengal, India. Phytotaxa 416(4): 294-300.

THIERS, B. [continuously updated] 2021. Index Herbariorum: a global directory of public herbaria and associated staff. New York botanical garden's virtual herbarium. http://sweetgum. nybg.org/ih/ 
VERBEKEN, A., E. HORAK AND D.E. DESJARDIN 2001. Agaricales of Indonesia. 3. New records of the genus Lactarius (Basidiomycota, Russulales) from Java. Sydowia 53(2): 261-289.

VERBEKEN, A. AND J. VESTERHOLT 2008. Lactarius. In: Funga Nordica (pp. 82-107). Nordsvamp.

VERBEKEN, A. AND J. VESTERHOLT 2012. Lactarius. In: Funga Nordica (p. 511). Agaricoid, Boletoid, Clavarioid, Cyphelloid and Gasteroid Genera. Nordsvamp, Copenhagen.

VERBEKEN, A., D. STUBBE, K. VAN DE PUTTE, U. EBERHARDT AND J. NUYTINCK 2014. Tales of the unexpected: angiocarpous representatives of the Russulaceae in tropical South East Asia. Persoonia 32: 13-24.

WANG, X.H. AND P.G. LIU 2002. Lactarius chichuensis and L. hirtipes, two easily confused species. Mycotaxon 84: 391-400.

WANG, X.H., K. DAS, J. HORMAN, V. ANTONIN, A. BAGHELA, D. CHAKRABORTY \& al. 2018. Fungal biodiversity profiles 51-60. Cryptogamie, Mycologie 39(2):211-257.
WISITRASSAMEEWONG, K., J. NUYTINCK, K.D. HYDE AND A. VERBEKEN 2014a. Lactarius subgenus Russularia (Russulaceae) in Southeast Asia, 1: species with very distant gills. Phytotaxa 158(1):23-42.

WISITRASSAMEEWONG, K., J. NUYTINCK, F. HAMPE, K.D. HYDE AND A. VERBEKEN 2014b. Lactarius subgenus Russularia (Russulaceae) in South-East Asia: 2. Species with remarkably small basidiocarps. Phytotaxa 188(4):181-197.

WISITRASSAMEEWONG, K., J. NUYTINCK, H.T. LE, E. DE CROP, F. HAMPE, K.D. HYDE AND A. VERBEKEN 2015. Lactarius subgenus Russularia (Russulaceae) in South-East Asia: 3. new diversity in Thailand and Vietnam. Phytotaxa 207(3):215-241.

WISITRASSAMEEWONG, K., B.P. LOONEY, H.T. LE, E. DE CROP, K. DAS, K. VAN DE PUTTE \& al. 2016. Lactarius subgenus Russularia (Basidiomycota, Russulales): novel Asian species, worldwide phylogeny and evolutionary relationships. Fungal Biology 120 (12): 1554-1581. 